\title{
Exploring Teaching Strategies to Attain High Performance in Grade Eight Mathematics: A Case Study of Chungcheongbuk Province, South Korea
}

\author{
Lambertus Gerhardus van der Wal \\ Zigiswa Mybert Monica Jojo \\ gerhardwal@gmail.com and jojozmm@unisa.ac.za
}

Doi:10.5901/mjss.2014.v5n23p1106

Abstract

This paper reports on a study conducted to investigate the teaching strategies used in the South Korean mathematical classroom and establish how they attain high performance in mathematics in comparison with other countries. The study focused mainly on the grade eight mathematics classroom and the teaching strategies used by the teachers as well as the students' perspective of the teaching strategies used. This was a case study in which both quantitative and qualitative research methods were used to collect data. Questionnaires consisting of a total of fifty closed questions to establish teaching strategies used, preferred learning styles from the students and how they felt about mathematics and the mathematical classroom were administered to two hundred and two grade eight students in sampled schools. An interview consisting of ten open questions to get feedback from the mathematics teachers on what teaching strategies they use in the classroom and what they think is the best strategy to use regarding mathematics were conducted with six grade eight teachers from those schools. The results showed that in the South Korean mathematics classroom a combination of direct instruction, practice and teacher guidance help the students to learn problem solving skills and to master mathematics. It was also revealed that students preferred that the teachers use mostly chalkboard instruction and that they practice solving problems with worksheets, exam paper questions and homework or private study. Also the study revealed that the average student studies mathematics about 6 hours a week and most of them go to afterschool academies to study more mathematics.

Keywords: direct instruction, practice, teacher guidance problem-solving skills, private study.

\section{Introduction}

The importance of mathematics is of substantial value and cannot be overlooked. Students compete on an international level and countries are rated on a ranking list regarding their performance at a particular level, one such example is the Trends in International Mathematics and Science Study (TIMSS). TIMSS is an assessment on fourth and eighth grade students' performance on mathematics and science across the globe. The following table displays the results of the studies that were performed for grade eight students in the past decade:

Table 1: Trends in International Mathematics and Science Study (TIMSS)

\begin{tabular}{|l|c|c|c|c|c|}
\hline Year of TIMMS & $\mathbf{1 9 9 5}$ & $\mathbf{1 9 9 9}$ & $\mathbf{2 0 0 3}$ & $\mathbf{2 0 0 7}$ & $\mathbf{2 0 1 1}$ \\
\hline Country ranked first: & Singapore & Singapore & Singapore & Taiwan & South Korea \\
\hline Ranking of South Korea & 2 & 2 & 2 & 2 & 1 \\
\hline Number of countries participating & 41 & 38 & 46 & 49 & 45 \\
\hline
\end{tabular}

From the table there is an indication that South Korean mathematical teaching strategies might prove more efficient and promote better mathematics learning hence more research on mathematics instruction used in this country may benefit other countries on mathematics instruction. Although there have been a lot of debates and movement away from the traditional methods of teaching, which mostly refers to knowledge being transferred from the teacher to the students, there are still schools (internationally) that use these methods and teaching strategies. Killen (2000) argues that there is not a single teaching strategy that is effective for all students in all situations. He defines the different teaching strategies as simply different ways of helping learners to learn or rather different ways of helping learners to achieve the learning outcomes that are required for understanding a particular concept. Sfard (1998) suggests that the teacher should adopt approaches that are less transmittal and more participatory for the learners, rather than doing the most talking and 
explaining to them. The notion of better strategies used in mathematics teaching is appealing but their implementation rewards learning and benefits the students. For example, most teachers associate participatory methods with group work, although these could also be used when doing some mathematical investigations and conjectures. There are other techniques that can be used to facilitate understanding of mathematical concepts, for example, getting the students to show their understanding through demonstration or verbal explanations of a given mathematics expression.

The 53rd International Mathematical Olympiad (IMO) held in 2012 in which 548 students representing 100 countries participated saw South Korea being ranked first with six gold medals. A lot of studies have been done on international mathematical instruction, with most focus on the curriculum (Vithal, R. Adler, J. \& Keitel, C. (eds.) 2005), teacher education, psychological or sociological perspectives of the education systems or tuition in second language, classroom size, resources, and others (Reddy, V., Kanjee, A., Diedericks, G. \& Winnaar, L. 2006), but to the researchers' knowledge, no study was found that focused on the teaching strategies that are currently used in the grade eight mathematics classroom. In South Korea this study addressed the basic elements needed in the classroom that can be implemented by all teachers to attain a higher student performance in mathematics.

It is the researchers' opinion that gaining better performance in mathematics does not require a whole paradigm shift in the curriculum but rather a use of better strategies and implementing them successfully to afford better learning and better performance. Thus, this paper intends to narrow the gap between high and low achieving countries by introducing teaching strategies that most countries can practice to attain a higher performance in mathematics.

\section{Literature Review}

Teaching strategies are the methods and techniques that the teacher uses to teach content knowledge in the classroom and transfer this knowledge to the students. According to Black (1999, p.120) to know the difference between rote learning and learning with understanding lies in the type of instructional strategy used in the classroom. Killen (2006) asserts that since learning is the process of acquiring new information, the teacher must choose a teaching strategy what will help the students to understand and remember the information, or think about it. The teacher sets the outcomes for the lesson and thus it is the teacher's responsibility to make sure that the information is directly aligned to the outcomes that the students should achieve at the end of each lesson. According to Killen (2006) the following teaching strategies apply to the modern classroom: (i) direct instruction, (ii) discussion, (iii) small-group work, (iv) co-operative learning, (v) problem solving, (vi) research, (vii) role play, (viii) case study and (ix) writing.

Orlich, Harder, Callahan, Trevison and Brown (2009) assert that as one plans to teach a subject, he/she must remember that the processes that students use to master the content of a lesson are just as important as the content itself. Vijayalakshmi (2004) asserts that there is a close relationship between teaching and learning and it is possible to modify, improve and develop teaching strategies for quality attainment. Thus it is important to see how South Korea has enhanced their strategies and to learn from it. In order to make sure that learning and understanding of mathematics occur in the classroom, it is essential that the correct learning styles and strategies are identified. It is important to incorporate strategies to help the students to learn mathematics with the learning styles that they prefer and these strategies should create opportunities for the students to use their own preferences.

Throughout history students have learned mathematics in different ways. Effective teaching practice has changed its face frequently as the demand for better education has increased. What was effective in the classroom twenty years ago might not be the best practice for the current classrooms. Before we started to focus on outcome based education the "Industrial era" shaped the education system to what we know as traditional education. The teaching strategies can best be understood through the education system they are used in. Different education systems have different demands and expectations so the teaching strategies are also influenced by these systems.

A subsequent strategy used by teachers related to traditional education is known as direct instruction. 'Direct instruction is often called "whole-group" or "teacher-led" instruction. Basically, the technique involves academic focus, provides few choices for student-initiated activities, tends to be large group-oriented, and emphasizes factual knowledge.' (Orlich, Harder, Callahan, Trevison and Brown, 2009, p.28) This teaching strategy has been considered to be phased out and newer and more group or whole class facilitating strategies were supposed to take its place. Although this is partly true there are still a lot of cases where direct instruction is part of the mathematics classroom in the present day.

Some teachers rely on direct instruction as a useful and an effective teaching strategy. Silver, Strong and Perini (2007, p.35) found that direct instruction can be useful to teach declarative content and is composed of a four-phase process that maximizes skill acquisition namely:

- Modeling -the teacher models and thinks aloud while performing the skill

- Directed practice - the teacher uses questions to lead students through the steps and helps them to see the 
reason behind the steps

- Guided practice - students generate their own leading questions while working through the steps; the teacher observes, coaches, and provides feedback and

- Independent practice -students work through more examples on their own

Silver, Strong and Perini further noted that this strategy worked because teachers who spent more time demonstrating and explaining procedures and skills are more effective than teachers who spend less time doing so.

\section{Education in South Korea}

These days there is a lot of concern regarding the South Korean education system. Mathematics has taken the blame for a lot of criticism regarding private spending or so-called "private education". Private education is mostly in the form of academies that teach the students after school. They prepare the students for the examinations and they provide extra mathematical problems and help the students if they are struggling. In these academies the classroom sizes are relatively small and students get more attention than in the school classroom. Private spending consists mostly of private tutoring and lessons at these private academies. Outside the schooling system Koreans spend 25 billion U.S. dollars (fully 150\% of the educational budget set aside by the government) on private education (Lee, 1999). In 1997 a national survey showed that the average middle school student (grades 7-9) had received about 10.3 hours per week of lessons, extracurricular, outside the school system (Kim, Yang, Kim \& Lee, 2001, p.50).

There are a lot of critics claiming that the South Korean education system regarding mathematics is not efficient. "Up to now, the most serious problem of mathematics education is that the mathematics classrooms in schools had been conducted without much concerning of students' ability to understand the contents, affective domain interests, aptitude and attitude and other attributes of the individual students" (Choe, 2003, p.79). The affective domain refers to the experience of feeling or emotion. The students' aptitude is a part of their competency to perform certain work at the level as required by the curriculum. The students' attitude and their motivation towards learning mathematics should be positively influenced by the teacher and classroom environment. The schools have been criticized as being monotonous. Woo $(2003$, p.2) stated that in the schools the mathematical abilities of students are so widely spread, in a class, that only about two thirds of the students in primary schools (grades 1-6), about half in middle schools (grades 7-9) and about one third in high schools (grades 10-12) understand the explanation given by teachers in class. As a result of this the private education market is growing, since students are trying to regain the necessary level of understanding of mathematics concepts.

\section{Mathematics in South Korea}

According to Pang (2009) many East Asian countries are considered to have teacher-dominated, content-orientated, and examination-driven mathematics instruction. Pang further notes that the mathematics classrooms feature whole-class teaching, large class sizes, and minimal student involvement. On the contrary when we look at the high mathematics scores that these Asian countries consistently achieve in international comparative studies (e.g., TIMSS), then it creates a question as to why they are achieving these high standards under these poor and unfriendly practices that are mentioned by Pang (2009).

According to the Programme for International Student Assessment (PISA) that is held by the Organisation for Economic Co-operation and Development (OECD) a total of sixty-five countries implemented the PISA 2009 assessment in 2009. According to the results of this assessment South Korea ranked overall second, second in reading, fourth in mathematics and sixth in science. On average South Korean students attend school 1020 hours a year once they reach age fifteen. The average OECD for hours a year is 902 , thus the South Korean students study about 118 hours more than average in a year. This does not include the additional time they spend at private institutions, academies. Although the South Korean students spend a lot of time in the classroom their interest in mathematics is not high. Korean students spend eight hours and 55 minutes per week on mathematics according to the Chosun newspaper (2009) in comparison to Finnish students who spend just four hours and 22 minutes per week on mathematics. Interestingly the Finnish scores were higher in the 2003 PISA assessment scores. Thus it can be seen that hours spent does not necessarily guarantee a high score. 


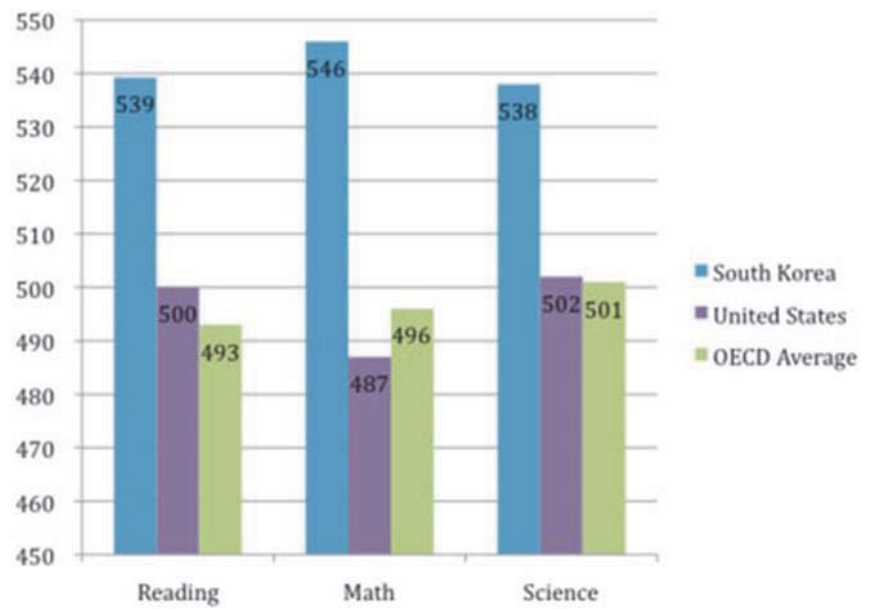

Figure 1: PISA 2009 Mean Scores by Country for Reading, Mathematics, and Science

According to Leung and Park (2005), although most people think that the passive learning in South Korean classrooms are not efficient and the apparently procedural teaching is ineffective, the students were actually engaged in meaningful exploration through their teachers who designed learning activities that kept them interested and gave them incentives to study harder. Also the study drew from the constructivists view, and as such the learners were keen to construct their own knowledge assisted by guidance from their teachers. However, results from the administered questionnaire indicated that the students are mostly not interested in mathematics and they don't seem to be motivated to study. This proves the negative perspective towards mathematics although on the other hand the positive results show that they learned and they have incentives to study harder. This would be associated with the guidance from the teachers and extra classes they get in private lessons.

\section{Research Methodology}

The study followed a case study where teaching strategies were explored within South Korean mathematics classroom. Data was gathered both qualitatively through interviews with the teachers and quantitatively using questionnaires administered to students to get their perspective on the teaching strategies and learning styles used in the mathematics classroom. The population of this study consisted of two hundred and two grade eight students from ten different middle schools in the Chungcheongbuk Province. One class per school was selected, with an average of twenty two students per class. From these ten schools there were six mathematics teachers who were willing to be interviewed and give their answers regarding teaching strategies in their classroom and what teaching strategies they thought could improve mathematical learning.

\section{Analysis and Discussion}

Quantitative methods were used to analyse the questionnaire administered to two hundred and two grade eight students in ten schools in the Chungcheongbuk province. The questionnaire was designed to give an insight into their knowledge of and skill with strategies and style through which the students preferred to learn. The questionnaire was made using a Likert scale. A Likert-type scale "requires an individual to respond to a series of statements by indication whether he or she strongly agrees, agrees, is undecided, disagrees, or strongly disagrees. Each response is assigned a point value, and an individual's score is determined by adding the point values of all the statements" (Gay, Mills, \& Airasian, 2009, p. 150-151).

The findings from the questionnaire showed that the responses from different students from the different schools were relatively similar. The responses to the questionnaires indicated that the teaching strategies were teacher orientated since the majority of the students felt that: The teacher (i) talks most of the time in the class, (ii) uses mostly chalkboard instructions to explain work in each lesson, and (iii) poses questions to the class as a whole for responses. Data collected also revealed that the resources used most include: (i) questions from past examination papers, (ii) worksheets and (iii) homework or private study. These are summarised in figure 2 below. 
Students preferences regarding teaching strategies included: (i) learning a strategy to solve the problem and then try it themselves, (ii) being taught as individuals, so that they can understand the content, (iii) listening to their teacher

while he or she explains the work, (iv) discovering the solutions to a problem for themselves, and (v) memorize the new work first so that they can recall it when needed.

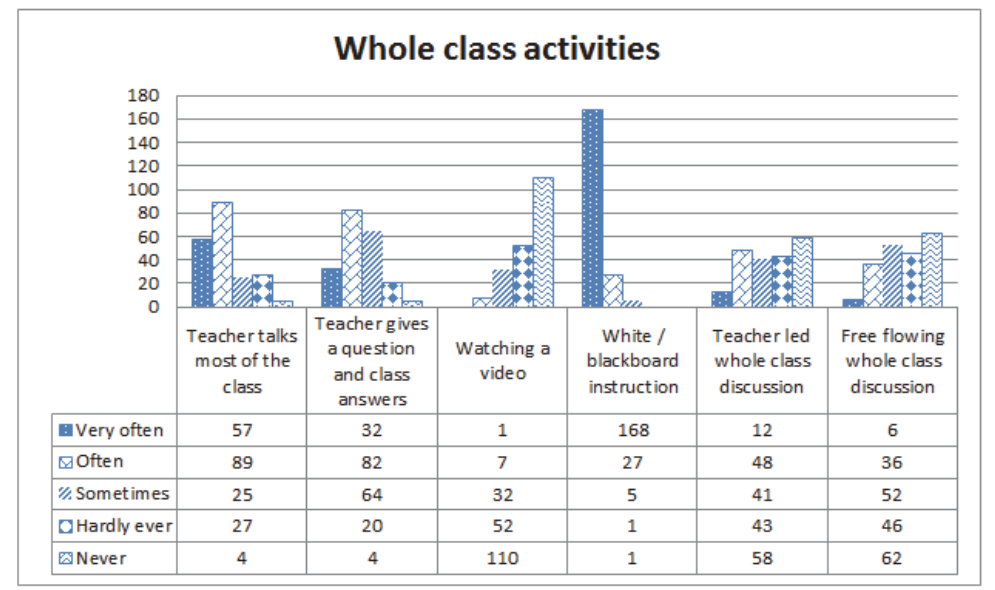

Fig 2: Students' responses on whole class activities

The students want clear outcomes to know what they are going to do in the class and they feel that they can identify areas of mathematics that they need to improve on, thus not needing feedback from the teacher. When it came to being motivated to learn mathematics they responded equally, the responses to both "agree" and "disagree" were even. Therefore they need guidance only from their teacher and afterwards they want to practice and try the concepts on their own.

Some individual activities that the students engaged in when learning mathematics are illustrated in fig 3 below.

The teachers mentioned that there is a big gap between the levels of students in the mathematics classroom. This gap is getting bigger and some students excel at mathematics while others are falling behind and losing focus. The main reason for this is that the curriculum is too broad with too much work to be done and after school academies that the students go to. The students who partake in extra classes get high grades and thus present a glossy finish to the mathematics classroom while there are a lot of students falling behind. The students who excel at mathematics practice harder, thus repetitive practice and they get more time to prepare for the examinations. The combination of direct instruction, practice and guidance can help to attain a high performance in mathematics. This is how some teachers responded to our questions in the interview:

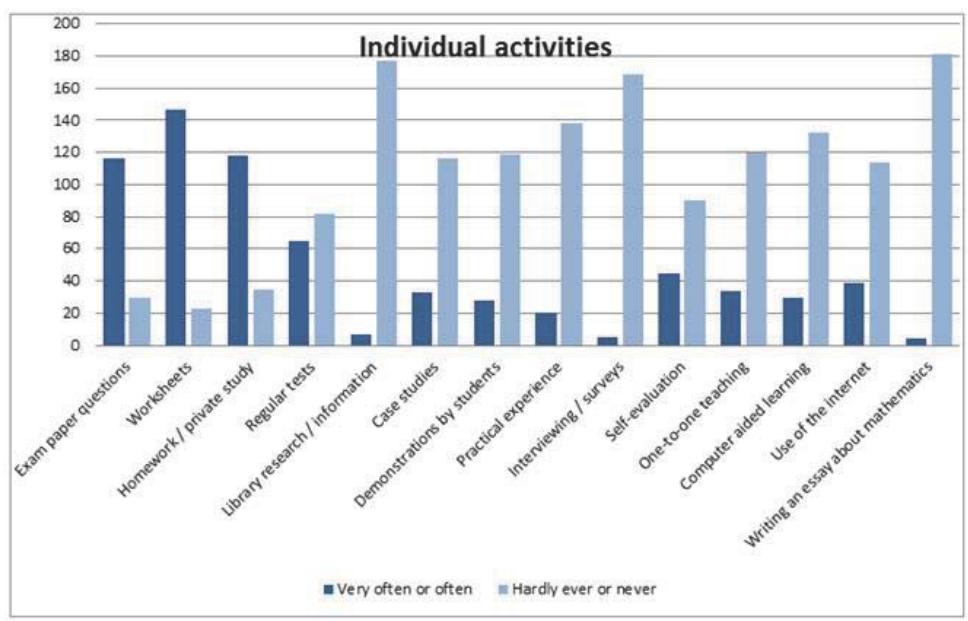

Fig 3: Students' responses on individual activities 
Researchers: Do you prefer to lead the class (direct instruction) or do you prefer to facilitate the students so that they work on their own or in groups?

T 1: I prefer to let students learn by themselves or do group activities. It is desirable for a teacher to suggest the right direction only while giving them an opportunity to solve problems themselves and arousing their interest.

T 2: I hope students can find out solutions and understand the ideas themselves. However, in reality, direct instruction is inevitable. Due to prior learning, students rarely have the opportunity to discover something new during class.

Researchers: Do you have a preferred teaching strategy? If so, explain why you prefer it.

T 1: I present a lot of mathematical problems and make students solve them and assess their tasks themselves.

T 2: I prefer direct guidance and to bring up questions in order for students to understand the fundamentals and practice them. After students finish their part, I organize what they learned and wrap up the class. Students can master it by solving many problems down the road.

Teachers felt that direct instruction is best used in big classrooms. Guided instruction was often mentioned as a good strategy to use when the student level is quite differentiated and the classes are not divided into levels. The differentiated classes consist of high performing students and low performing students mixed into one class. They felt that it is best to first show the examples on the board and to explain them, and then letting the students practice by themselves by using the new concepts to master the problems while the teacher is guiding the students while they are busy working individually. Practice is another fundamental part that they mentioned that is needed in the mathematics classroom. A teacher can only teach a student the new concepts and help them to understand it via examples but the students should then master the new concepts by implementing it themselves and practicing it. Most of the teachers felt that the curriculum is too full and that the pressure is too much to accomplish it all in one year. They feel that the higher level students can explore mathematics more deeply on their own. Some responses to the interview included:

Researchers: South Korea is known for their high achievement in mathematics. What do you think is the reason why South Korean students are good in mathematics?

T 1: Systematic education is being implemented step by step since childhood. General atmosphere in Korean society put a great importance on studying and students can get an education right for their age.

$T$ 2: Parents' educational zeal. University entrance examination, still-existing special treatment given to those who graduate from so-called elite universities.

$T$ 3: The main reason is thought to be years of learning of various mathematics, problem-solving skills starting in elementary schools. Even though the general outcome is outstanding, the gap between those excellent and those who are not is huge.

T 4: In Korea, mathematics is the subject that can decide a student's life. Korean students think they cannot enter the elite universities without studying mathematics. They study continually and patiently, investing more time to math than students in other countries. That explains why Korean students get better results.

The responses above cite the importance of societal involvement in the learning of mathematics in South Korea. This suggests that mathematics teaching and learning is prioritised in this country, where the parents have a zeal for their children's education and the general atmosphere in Korean Society puts great emphasis on studying. Thus motivation to study mathematics is orchestrated from home and if students perform badly the parents urge them and enrol them for private tuition classes.

\section{Conclusion}

If the teacher wants to apply different teaching strategies then he/she needs to gradually build up his/her teaching expertise. This will help the teacher to make the right decisions as to what approach and strategy to use. The teacher's planning should always start with the important outcomes that he or she wants the students to achieve. After the teacher has identified the outcomes then he/she can start to think about the content that he/she wants to select to help students achieve these goals and the teaching strategies that the teacher might use.

From the literature reviewed and responses from both students and teachers, it appears that in order to best understand teaching strategies the teacher needs to understand the different ways in which students learn, what learning strategy or method they prefer and he/she should plan to use the correct strategy to make sure the desired outcomes are reached. When focusing on the South Korean classroom it is noticeable that there are many faults and problems that 
critics emphasize and complain about, but it is important to not focus at what is not working but to rather focus on what can be learned and to look deeper at what lies underneath to get a better understanding of how their teaching strategies influence the students' mathematic ability.

\section{References}

Anonymous. 2009. Korean Youth Study Longest Hours in OECD. http://english.chosun.com/site/data/html_dir/2009/08/10/ 2009081000200.html. 26 May. 2013.

Black, P. 1999. Assessment, Learning Theories, and Testing System. In: P. Murphy (ed), Learners, Learning, and Assessment .p.118134. London: Paul Chapman Publishing in Association with The Open University.

Choe, Y.H. 2003. The First Curriculum of Mathematics in Korea for the New Millennium.

Journal of the Korea Society of Mathematical Education Series D: Research in Mathematical Education, Vol. 7, No.2, June 2003, p. 7390.

Gay, L.R. Mills, G.E \& Airasian, P. 2009. Educational research: Competencies for analysis and applications. Columbus, OH: Merrill.

Killen, R. 2000. Teaching strategies for Outcomes-based education. Juta\&Co.Ltd

Killen, R. 2006. Effective teaching strategies, Fourth Edition. Cengage Learning Australia.

Kim, Y. C., Yang, S.S., Kim, Y. H. \& Lee, J. H. 2001.Policy Measures for Resolving the Problem of Overheated Private Tutoring. KEDI Research Report CR 2001-15. Seoul: Korean Educational Development Institute (KEDI).

Lee, J. (1999): Missing links in international education studies: Can we compare the U. S. with East Asian countries in the TIMSS? International Electronic Journal for

Leadership in Learning, 3(18), 1-11. http://www.ucalgary.ca/ iejll

Leung, F.K.S., Park, K. 2005. Behind the High Achievement of Students: A Study of Mathematics Lessons in Korea, report of a project funded by the World Bank-GDN Regional Research Competition, KEDI.

Orlich, D.C. Harder, R.J. Callahan, R.C. Trevisan, M.S. Brown, A.H. 2009.

Teaching Strategies: A Guide to Effective Instruction, Ninth Edition. Cengage Learning.

Pang, P. (2009). Strategy for the development of a global city: Study abroad in Singapore. In R. Lewin (Ed.), The handbook of practice and research in study abroad: Higher education and the quest for global citizenship (p. 230-246). New York, NY: Routledge.

Reddy, V. Kanjee, A. Diedericks, G. \& Winnaar, L. 2006. Mathematics and Science Achievement at South African Schools in TIMSS 2003. HSRC Press.

Sfard, A. 1998 On two metaphors for learning and the dangers of choosing just one. Educational Researcher, 27(2), pp. 4-13

Silver, H., Perini, M., \& Strong, R. 2007.The Strategic Teacher: Selecting the Right Research-Based Strategy for Every Lesson. Alexandria, VA: Association for Supervision and Curriculum Development.

Vithal, R. Adler, J. \& Keitel, C. (eds.). 2005. Researching mathematics education in South Africa: perspectives, practices and possibilities. HSRC Press.

Vijayalaksmi, K.S. 2004. 'Teaching Strategies: Present Practices and Future Directions' in Singh, R.P. (ed.). Teaching strategies.APH Publishing.

Woo, J. H. 2003. Problems and looking for direction of improvement Mathematics curriculum 9 (in Korean). In: Korea Society of Mathematical Education (Ed.), Mathematical Discovery: The 40th Incentive Seminar on Mathematics Education (held at Cheongju National University of Education, 2003. 4. 26). p. 1-24. Seoul: Korea Society of Mathematical Education. 